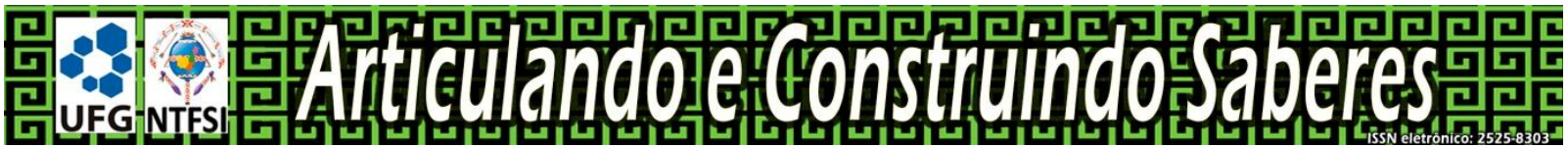

DOI:10.5216/racs.v5.66611

\title{
Estudo sobre o potencial de cartografias interculturais para a emergência e consolidação de novas bases epistêmicas
}

\section{Alexandre Herbetta ${ }^{1}$}

Mariano Baez Landa ${ }^{2}$

\section{RESUMO}

O texto a seguir reflete brevemente sobre o potencial da cartografia enquanto método. Neste sentido, na dinâmica do mapeamento proposto pode-se identificar e sistematizar aspectos centrais de projetos contra coloniais e, assim, propor, executar e avaliar ações e políticas mais consistentes sobre a questão. Percebe-se que um movimento central no processo de construção de cartografias interculturais é a emergência de novas bases epistêmicas.

PALAVRAS-CHAVE: Epistemologia. Cartografia. Interculturalidade.

\section{Estudio sobre el potencial de la cartografía intercultural para el surgimiento y consolidación de nuevas bases epistémicas}

\section{RESUMEN}

El siguiente texto reflexiona brevemente sobre el potencial de la cartografía como método. En este sentido, en la dinámica del mapeo propuesto, es posible identificar y sistematizar aspectos centrales de los proyectos contra hegemonícos y así proponer, ejecutar y evaluar acciones y políticas de manera más consistente en el tema. Se advierte que un movimiento central en el proceso es el surgimiento de nuevas bases epistémicas.

PALABRA CLAVE: Epistemología. Cartografía. Interculturalidad.

\section{Introdução}

Este texto busca refletir sobre a potencialidade presente na cartografia intercultural proposta, neste dossiê, para o entendimento da emergência de novas bases epistêmicas. Buscamos, neste processo, realizar uma espécie de autorreflexão no sentido da afirmação de Dussel sobre Freire, acerca do sujeito da educação que "se volta reflexivamente sobre si mesmo"

\footnotetext{
${ }^{1}$ Universidade Federal de Goiás (UFG), Goiânia, Goiás, Brasil. E-mail: alexandre herbetta@ yahoo.com.br.

${ }^{2}$ Centro De Investigaciones y Estudios Superiores en Antropologia Social (CIESAS), Veracruz, México. E-mail: alexandre_herbetta@yahoo.com.br.
} 
(DUSSEL, 2000, p. 435). Para Freire "é preciso que (o sujeito) seja capaz de, estando no mundo, saber-se nele. Saber que, se a forma pela qual está no mundo condiciona sua consciência deste estar, é capaz sem dúvida, de ter consciência desta consciência condicionada" (FREIRE, 1983, p. 16).

Queremos saber tanto sobre os resultados e impactos dos projetos mencionados na vida das pessoas, em territórios originários e não originários, quanto sobre nós mesmos, nossos projetos, cursos e acerca das potencialidades e limites das instituições nas quais atuamos. Uma pergunta central é como romper com a violência epistêmica presente desde sempre em currículos, práticas pedagógicas e dinâmicas acadêmicas institucionais. Para Vitarelli,

tratando das universidades latino-americanas algumas universidades públicas aceitaram o desafio e lançaram, na década recente, várias formas de pensar sobre essa nova realidade. Embora o currículo seja o centro do tratamento do assunto, para nós, nessa oportunidade o que nos interessa mostrar é o lado sociopolítico que inaugura outras práticas e modos de agir (VITARELLI, 2017, p.46).

\section{Noções importantes}

Os projetos contra coloniais mapeados aqui e, usualmente, possuem como base noções como interculturalidade crítica (WALSH, 2013), transdisciplinaridade (KAMER, 2013), decolonialidade e diferença colonial (MIGNOLO; TLOSTANOVA, 2012), transformações epistemológicas (CUSIQUANQUI, 2018), processos de coteorização (RAPPAPORT, 2007; SARTORELLO, 2014) dentre outras.

Vale mencionar, ainda, tal como afirmam Dussel (2016) e Castro-Gómez (2019), que se deve atentar para a superação de uma dicotomia limitante muitas vezes observada nos estudos em referência, qual seja, entre uma postura que apenas reafirma a potencialidade de conhecimentos originários, posicionados muitas vezes de maneira isolada e distante dos processos históricos aos quais se vinculam e outra postura que apenas deseja integrar outras epistemologias de resistência, criação e transformação a estruturas presentes na modernidade, vista ainda de forma homogênea.

A cartografia aqui desenvolvida demonstra marcantemente que a reificação desta dicotomia seria apenas mais uma maneira equivocada e dualista de tratar a questão.

Assim, o conceito estrito de "transmoderno" indica essa novidade radical que significa o surgimento - como se a partir do nada - da exterioridade, da alteridade, do sempre distinto, de culturas universais em desenvolvimento, que assumem os desafios da Modernidade e, até mesmo, da pós-modernidade euro-americana, mas que respondem 
a partir de outro lugar, other location (Dussel, 2002), do ponto de sua própria experiência cultural, diferente da euro-americana, portanto capaz de responder com soluções completamente impossíveis para a cultura moderna única (DUSSEL, 2019, p.63).

Nesta direção, para Castro-Gómez (2019), uma estratégia para a superação da dicotomia pode ser a apropriação da universalidade "abstrata" do republicanismo moderno e sua transformação em uma universalidade "concreta", por meio da luta política contra a modernidade eurocentrada.

Cabe então pensarmos nas modernidades possíveis e, portanto, na maneira como as potencialidades epistemológicas e ontológicas originárias podem participar e propor novas construções societárias. A noção mesma de novas bases epistêmicas, centro deste dossiê, como se verá, supera o limite da dicotomia em tela e propõe a possibilidade de um pluriverso.

A cartografia em tela permite, então, a sistematização de alguns elementos que podem ser destacados em processos contra coloniais, de modo que se pode, então, refletir de maneira mais aprofundada sobre outras experiências, práticas, propostas e políticas. Pode se pensar, inclusive, de maneira mais concreta na possibilidade da transmodernidade.

\subsection{Território}

O território é o centro das experiências apresentadas. Ter o território como base, aponta para um aspecto fundamental das epistemologias ancestrais e originárias, qual seja uma ruptura com um dos eixos de uma epistemologia ocidental, a dicotomia natureza-cultura. Aponta, também, para um ponto nodal da modernidade eurocentrada, a questão da terra e do território.

Para Ailton Krenak, liderança indígena no Brasil, a crise que vivemos tem a ver com o fato de que

fomos nos alienando desse organismo de que somos parte, a Terra, e passamos a pensar que ele é uma coisa e nós, outra: a Terra e a humanidade. Eu não percebo onde tem alguma coisa que não seja natureza. Tudo é natureza. O cosmos é natureza. Tudo em que eu consigo pensar é natureza (KRENAK, 2020, p.10).

Krenak lembra, ainda, que,

assim como aquela senhora hopi que conversava com a pedra, sua irmã, tem um monte de gente que fala com montanhas. No Equador, na Colômbia, em algumas dessas regiões dos Andes, você encontra lugares onde as montanhas formam casais. Tem mãe, pai, filho, tem uma família de montanhas que troca afeto, faz trocas. E as pessoas que vivem nesses vales fazem festas para essas montanhas, dão comida, dão presentes, ganham presentes das montanhas. Por que essas narrativas não nos entusiasmam? Por 
que elas vão sendo esquecidas e apagadas em favor de uma narrativa globalizante, superficial, que quer contar a mesma história para a gente? (KRENAK, 2020, p.10).

Segundo Gersem Luciano Baniwa, intelectual e líder indígena (2019), entretanto, a grande marca do ocidente é não entender, não aceitar, e atacar tais princípios e relações. Segundo o autor, o ocidente distingue os dois domínios, natureza e cultura, objetificando o primeiro. Para o autor, esta é a base da possibilidade de exploração predatória do planeta e da consequente degradação da vida. Conforme Luciano, ainda, ao objetificar a natureza, legitimando a predação da mesma, a matriz epistemológica ocidental busca apagar a espiritualidade presente nos seres, espécies e objetos do mundo.

A ciência acadêmica ocidental divide e opõe índio e branco, homem e mundo, sociedade e natureza, corpo e espírito, bem e mal, rico e pobre, gordo e magro, conhecimento tradicional ou popular e conhecimento científico e assim por diante. É necessário a gente entender bem esse tipo de pensamento e, principalmente, ter muito cuidado para não acreditar nele como verdade absoluta. Os conhecimentos e pensamentos indígenas são muito diferentes e não se baseiam nesse dualismo por oposição. Acreditar e seguir indistintamente o pensamento ocidental na escola e na academia pode produzir estragos profundos irreversíveis para os nossos conhecimentos e modos de vida indígena (LUCIANO BANIWA, 2019, p. 3).

Nesta direção para Baniwa "o pensamento ocidental se considera autossuficiente e o único verdadeiro. O pensamento indígena não. Este utiliza a ideia de complementariedade de pensamento, o que significa admitir a necessidade de outros pensamentos e a limitação do seu próprio conhecimento" (LUCIANO BANIWA, 2019, p.13-14).

\subsection{O problema da interculturalidade}

A proposição de Baniwa, acima, aponta para novos modos de interação e outras relações possíveis. Indica, inclusive, o desmonte da estrutura de poder eurocentrada vigente. Nesta direção, os projetos mapeados apresentam igualmente uma experiência de escuta profunda, sendo pautados em diversas epistemologias originárias, desvelando o desafio de se estabelecer uma relação adequada entre o particular e o universal.

Como aceder, entretanto, e propor mudanças com base em outros sistemas de pensamento, se por um lado boa parte das equipes de pesquisa ainda são constituídas majoritariamente por não indígenas e, por outro, tais experiências se dão muitas vezes de maneira institucional, dinâmica pautada em grande parte em processos de violência epistêmica?

Este processo é bastante tortuoso, pois segundo Kusch, 
requer uma mudança de direção do olhar comum. Talvez um olhar provinciano que vai para a cidade, ou o de um homem do povo que vê aqueles outros acima, ambos notando o pico de gelo emergindo da água. E é o olhar do índio que contempla com um sorriso a passagem do gringo preso naquele carro que denuncia o desejo deste de ser alguém (KUSCH, 2015, p. 460-461).

Daniel Munduruku busca igualmente responder a questão:

A resposta não é simples, mas ouso dizer que as pedagogias inclusivas não passam de arremedos na solução de um "problema" indígena, pois elas salientam ainda mais a falta de uma real compreensão do que seja um povo indígena e suas verdadeiras necessidades. Mais: elas escancaram a falta de um pensamento governamental a respeito do tratamento que estes grupos étnicos devem ter. Ou seja, revelam que o governo não tem competência para definir o que ele pensa a respeito dos indígenas. Ou será que alguém de governo já se posicionou de forma inequívoca sobre as intenções políticas com relação aos indígenas? Como saber quais as reais intenções políticas oficiais sobre os nativos? Ora, o que vem acontecendo são justificativas pedagógicas do tipo inclusivistas (a diversidade na universidade), ou paliativas (programas estaduais de magistérios indígenas) ou ainda neoliberais (formação de técnicos para suprir o mercado). E qual o propósito disso? Seriam muito diferentes dos projetos de "inclusão" que faziam os militares em sua política de incorporação à sociedade brasileira? (MUNDURUKU, 2017, p.1).

A própria noção de interculturalidade é problemática, frequentemente usada como um adjetivo que qualifica magicamente qualquer abordagem e ação que afirme reconhecer e atender à diversidade cultural, usando um discurso de defesa do politicamente correto a todo custo das tradições ancestrais, costumes e conhecimentos dos chamados povos originários, como um imperativo ético-político contra as ameaças do capitalismo neoliberal.

A interculturalidade é classificada, às vezes, inclusive, como uma nova etapa do desenvolvimento humano, como um projeto cultural alternativo que pressupõe um plano horizontal de comunicação, intercâmbio e cooperação do conhecimento. Essa interculturalidade idílica, entretanto, não corresponde à experiência do mundo vivo e vivido, atravessado pelas categorias de raça, gênero, classe e sexualidade, e onde as relações sociais são baseadas em atrito, conflito, negação do outro, racismo, desigualdade econômica e social, homofobia, sexismo, violência e medo (BÁEZ LANDA, 2018, p.41). Interculturalidade é, concretamente, conflito (GASCHÉ et al., 2008).

A própria incorporação do conhecimento originário em programas de educação superior intercultural apresenta enormes desafios, pois as dinâmicas institucionais existentes são elaboradas em espaços marcados por relações interétnicas em permanente tensão. Uma verdadeira educação democrática e intercultural necessita superar o relativismo de raça, etnia e cultura, romper com os universalismos e se apoiar na noção de pluriversidade. Para CastroGómez, o universalismo corresponde "a um conjunto de valores dados a priori que preexistem 
à política e que são usados como arma para subjugar a outras culturas e formas de vida tidas como bárbaras" (CASTRO-GÓMEZ, 2019, p.78, tradução do autor).

\subsection{Pluriepistemologia}

Esta busca por aceder, dialogar e entender outros modos de ser na América Latina ou às noções próprias deste território é antiga e remonta à obra do filósofo argentino Rodolfo Kusch, desde a década de 1950. Dussel, expoente da filosofia da libertação, traz à tona, na mesma época, igualmente, o simbolismo da cultura popular e busca ir mais além do logos ocidental.

Com variações, divergências e particularidades marcantes e importantes, a proposição da superação deste desafio, segue e se estende a contribuições atuais observáveis desde na etnologia indígena, na perspectiva do giro ontológico que busca sistematizar outras ontologias e tem como referência o trabalho de Eduardo Viveiros de Castro e a noção de perspectivismo, até os estudos do grupo modernidade/colonialidade, e o giro epistêmico, que tem como base a tríade colonialidade do ser, saber e poder, ambos elaborados especialmente desde a década de 1990.

Este movimento de aprofundamento passa, igualmente, por outros aportes e contribuições, como as presentes na práxis do Exército Zapatista de Libertação Nacional no México, nas propostas do Grupo de Historiadores Mapuche no Chile, na proposição constitucional da plurinacionalidade no Equador e na Bolívia, e na apropriação, por povos originários, de instituições de ensino no Brasil, como a universidade e a escola.

Como se vê, esta busca é um eixo consistente e desafiador para as instituições de ensino e pesquisa e para projetos contra coloniais.

A filosofia latino-americana, como filosofia da libertação, descobria seu condicionamento cultural (pensava-se a partir de uma cultura determinada), mas também articulada (explícita ou implicitamente) a partir dos interesses de classes, grupos, sexo, raça etc. determinados. A location havia sido descoberta e era a primeira questão filosófica a ser tratada. O diálogo intercultural havia perdido sua ingenuidade e passou a ser compreendido como sobre determinado por todo o período colonial. De fato, em 1974 iniciamos um "diálogo" intercontinental "Sul-Sul" entre os pensadores da África, Ásia e América Latina, cuja primeira reunião foi realizada em Dar-EsSalaam (Tanzânia) em 1976. Esses encontros deram-nos um novo panorama sobre as grandes culturas da humanidade (DUSSEL, 2016, p.52).

Em todos os casos, mesmo com enormes diferenças e divergências, tenta-se problematizar o uso de categorias e conceitos de uma matriz europeia para o entendimento de mundo latino-americano e se propõe novas hermenêuticas. 
Lentamente, embora a questão tenha sido vislumbrada intuitivamente desde o final dos anos 1950, passa-se de (a) uma obsessão por "situar" a América Latina na história mundial - o que exigiu reconstruir completamente a visão da denominada história mundial - (b) para o questionamento sobre a visão padrão (geração hegeliana) da mesma história universal que havia nos "excluídos", já que, por ser "eurocêntrica", construía uma interpretação distorcida não só de culturas não europeias, mas, e esta conclusão era imprevisível na década de 1950 e não era esperada a priori, igualmente interpretava equivocadamente a própria cultura ocidental (DUSSEL, 1995, p.56).

Abre-se, então, a possibilidade de efetivação de um novo repertório conceitual vinculado à "imaginação conceitual, sensível à criatividade e reflexividade inerentes à vida de todo coletivo, humano e não-humano" (VIVEIROS DE CASTRO, 2015, p. 25) o qual é relevante para se (re) pensar a educação formal e informal, regimes de produção de conhecimento, o estado-nação e o planeta.

\title{
1.4 Metodologias colaborativas
}

Neste cenário, um possível movimento de aprofundamento ao desafio acima exposto é o desenvolvimento de metodologias participativas, importantes na região em tela desde ao menos o trabalho de Fals Borda (2015). Para Chilisa,

\begin{abstract}
pesquisas participativas permitem a grupos vulneráveis e desempoderados compartilharem coletivamente e refletirem sistematicamente sobre seus conhecimentos, suas experiências de vida e seus contextos de modo a usarem conscientemente seus conhecimentos com centro de ação e planejamento (CHILISA, 2012, p. 8, tradução do autor).
\end{abstract}

Os projetos mapeados nesta cartografia se constituem, então, “desde abajo”, apontando para outras dinâmicas possíveis tanto do ponto de vista metodológico quanto teórico. Segundo Aguilar há uma preocupação evidente

de entender as formas da política e do político que são praticadas e pensadas desde abaixo e que se tornam visíveis tanto em momentos mais enérgicos da luta social como nos esforços cotidianos para sustentar material e simbolicamente a reprodução da vida social (AGUILAR, 2018, p. 13).

Para Aguilar, ainda,

a redescoberta e reprodução de um senso de inclusão coletiva, muitas vezes herdada, mas sempre re-gerada a partir da deliberação sistemática de um objetivo ou finalidade coletiva (quem e pelo que produzem, reproduzem e redescobrem ou amplificam o comum?) se impõe na criação de mecanismos de equalização e/ou equilíbrio - não 
meramente formais - em relação ao que está sendo produzido e/ou se deseja que seja produzido como comum (AGUILAR, 2018, p.125).

Este processo revelador e inovador, de busca do coletivo, mas também tenso e conflituoso, pode gerar transformação. Para Rappaport, "mais significativo é o espaço que abre o processo de coteorização com os grupos que estudamos, proporcionando aos nossos interlocutores e a nós mesmos, novas ferramentas conceituais para dar sentido às realidades contemporâneas" (RAPPAPORT, 2007, p. 201). Sartorello, um dos coordenadores do projeto Milpas Educativas, no mesmo sentido, afirma que o processo de co-teorização intercultural encontra

\begin{abstract}
o seu núcleo gerador (seu coração, dizem os maias) nos códigos vivos através dos quais meus colaboradores maias sintetizam os princípios da pedagogia indígena aprendida e praticada na vida e nas escolas da comunidade. Estes códigos constituem o ponto de partida para o diálogo com outras categorias - que temos chamado fusionadas - as quais expressam a união de horizontes dos diferentes sujeitos participantes (assessores kaxlanes e colaboradores indígenas), bem como com aquelas categorias teóricas produzidas por outros autores e que são as que permitem ampliar o alcance teórico da co-teorização intercultural (SARTORELLO, 2014, p. 15).
\end{abstract}

\title{
Considerações
}

Neste contexto, a cartografia intercultural apresentada potencializa a emergência de novas bases epistêmicas, as quais se constituem em metodologias colaborativas e buscam transformar os modos de pensar e produzir o universo, "desde abajo", tomando como base outras categorias, conceitos, métodos de pesquisa e práticas, desmontando o espírito universalista monocultural e monoepistêmico que sustenta a estrutura de poder vigente (PIMENTEL; HERBETTA, 2018).

Para Cusiquanqui, em relação às possibilidades reais de transformação social, "para realmente mudar as coisas, você tem que mudar a episteme, a matriz da cultura" (CUSIQUANQUI, 2018, p. 15).

A cartografia permite, então, sobretudo, se pensar sobre reais possibilidades de transformação epistemológicas e políticas, por meio de experiências concretas desenvolvidas em Abya Yala, em direção a "um projeto societário alternativo ao capitalismo global" (SANTOS, 2005, p.30). Permite o que Santos et al (2016, p. 201) chamam de retomar e consolidar conhecimentos plurais e contra hegemônicos de modo a colaborar com experiências políticas relacionadas às discussões contemporâneas sobre a questão indígena latino-americana 
que se articulam às concepções atuais de educação escolar, interculturalidade e processos de descolonização.

Para Wallerstein, "cá estamos nós: à beira de uma reestruturação epistemológica fundamental, uma reunificação de métodos de pesquisa nos diferentes campos do conhecimento" (WALLERSTEIN, 2004, p. 52).

Colocamo-nos, portanto, no movimento maior de contra colonização, entrelaçando redes constituídas e em desenvolvimento a outras tantas redes, estabelecidas em distintos períodos, territórios e em diferentes estágios de atuação, alimentando e retro alimentando processos de transformação social, do ponto de vista epistemológico, ontológico, pedagógico e político.

Vale notar que a cartografia fortalece redes que se relacionam igualmente a outras tantas redes contemporâneas de pesquisa, produção de conhecimento e atuação, as quais possuem perspectivas particulares e distintas, e busca se colocar em diálogo e contribuição com outros mundos possíveis.

Tal tarefa é ainda mais urgente em um mundo impactado pela pandemia da Covid-19 que marca claramente os limites do avanço desenfreado do modo capitalista de produção e da própria economia de produção de uma desigualdade anômala, racista, centro e praga do mundo contemporâneo. Mais do que nunca é necessário problematizar a produção e reprodução do conhecimento e das instituições que acabam por excluir cosmogonias e conhecimentos ancestrais, formatando, por um lado, políticas públicas e, por outro, a mente e o corpo de todxs.

\section{Referências}

AGUILAR, Raquel. Comunalidad, tramas comunitarias y producción de lo común. Debates contemporáneos desde América Latina/Raquel Gutiérrez Aguilar (Coord.). Oaxaca, México: Colectivo Editorial Pez en el Árbol, Editorial Casa de las Preguntas, 2018.

BÁEZ LANDA, M. Universidades interculturales en México: comentarios desde una mirada antropológica. In: BAEZ, M.; HERBETTA, A. (Org.) Educaçao indigena e interculturalidad. Um debate epistemológico e político. Goiânia: CIESAS-UFG. Disponível em: https://www.cegraf.ufg.br/up/688/o/ebook_educacao_indigena.pdf.

BERTELY, Maria; GASCHE, Jorge; PODESTA, Rossana. Educando en la diversidad cultural. Investigaciones y experiencias educativas interculturales y bilingües. Ecuador: Ediciones Abya-Yala, 2008.

CASTRO-GÓMEZ, Santiago. El tonto y los canallas: notas para un republicanismo transmoderno. Bogotá: Pontifícia Universidad Javeriana, 2019. 
CUSIQUANQUI, Silvia. Un mundo ch'ixi es posible. Ensayos desde un presente en crisis. Buenos Aires: Tinta Limón, 2018.

CHILISA, Bagele. Indigenous Research Methodologies. SAGE Publications, 2012.

DIETZ, Gunther; GUILHERME, Manuela; SANTOS, Boaventura de Sousa. Da universidade à pluriversidade: reflexões sobre o presente e o futuro do ensino superior. Revista Lusófona de Educação, 31, p. 201-212, 2016.

DUSSEL, Enrique. Ética da Libertação na idade da globalização e da exclusão. Petrópolis: Editora Vozes, 2000.

DUSSEL, Enrique. Transmodernidade e interculturalidade: interpretação a partir da filosofia da libertação* Enrique Dussel. Revista Sociedade e Estado, v. 31, n. 1, jan./abr. 2016.

FREIRE, Paulo. Educação e Mudança. Rio de Janeiro: Paz e Terra, 1983.

FALS BORDA, Orlando. Una sociología senti-pensante para América Latina. In: FALS BORDA, Orlando; MONCAYO, Víctor Manuel. Antología y presentación. México, D. F.: Siglo XXI Editores; Buenos Aires: CLACSO, 2015.

GASCHÉ, Jorge; BERTELY, Maria; PODESTA, Rossana. Educando en la diversidad cultural. Investigaciones y experiencias educativas interculturales y bilingües. Ecuador: Ediciones Abya-Yala, 2008.

KAMER, Julio. Xahtã mẽ pahte amnhĩ nhĩpêx ho hihtỳx: relações entre queimadas e cantorias no território Apinaje. 2013. Monografia (Curso de Educação Intercultural) - Núcleo Takinahakỹ de Formação Superior Indígena, Universidade Federal de Goiás, Goiânia, 2013.

KRENAK, Ailton. Ideias para adiar o fim do mundo. São Paulo: Cia das Letras, 2020.

MADINA V. Tlostanova, MIGNOLO. Learning to Unlearn: decolonial reflections from eurasia and the Americas. The Ohio State University Press. Series: Transoceanic Studies, 2012.

LUCIANO BANIWA, Gersem José dos Santos. Educação para manejo do mundo. Entre a escola ideal e a escola real no Alto Rio Negro. Rio de Janeiro: LACED/Contracapa, 2014.

MARTINS Paulo Henrique. Sociologia na América Latina: giros epistemológicos e epistêmicos. Revista Sociedade e Estado, v. 34, n. 3, set./dez. 2019.

MUNDURUKU, Daniel. A escrita e a autoria fortalecendo a identidade. Disponível em: http://pib.socioambiental.org/pt/c/iniciativas-indigenas/autoriaindigena/ a-escrita-e-a-autoriafortalecendo-a-identidade. Acesso em: 30 dez. 2009.

PIMENTEL DA SILVA, Maria do Socorro; HERBETTA, Alexandre. Atualizando, juntando e esticando a universidade: considerações sobre a possibilidade de uma pluriversidade. Em: Pracs: Revista Eletrônica de Humanidades do Curso de Ciências Sociais da Unifap. Disponível em: 
https://Periodicos.Unifap.Br/Index.Php/Pracs. Macapá, v. 11, n. 1, p. 11-26, jan./jun. 2018. ISSN 1984-4352.

RAPPAPORT, J. Más allá de la escritura. La epistemología de la etnografía em colaboración. Revista Colombiana de Antropología, 43, p. 197-229, 2007.

SARTORELLO, Stefano Claudio. La co-teorización intercultural de un modelo curricular en Chiapas. México Revista Mexicana de Investigación Educativa, RMIE, v. 19, n. 60, p. 73-101, 2014. ISSN 14056666.

SANTOS, Boaventura de Sousa; DIETZ, Gunther; GUILHERME, Manuela. Da universidade à pluriversidade: reflexões sobre o presente e o futuro do ensino superior. Revista Lusófona de Educação, 31, p. 201-212, 2016.

SANTOS, Boaventura de Sousa. A Universidade no Séc. XXI: para uma reforma democrática e emancipatória da universidade. Educação, Sociedade \& Culturas, 23, p. 137-202, 2005.

VITARELLI, Marcelo Fabián. Pensar las prácticas pedagógicas en el sur. Buenos Aires: Editorial Autores de Argentina, 2017.

VIVEIROS DE CASTRO, Eduardo. Metafísicas Canibais: elementos para uma antropologia pós-estrutural. São Paulo: Cosac Naify, 2015.

WALLERSTEIN, Immanuel. Las incertidumbres del saber. Barcelona: Editorial Gedisa, 2005.

WALSH, Catherine. Pedagogías decoloniales: practicas insurgentes de resistir, (re) existir y (re) vivir. Serie Pensamiento Decolonial, 2013.

Submetido em 13 de novembro de 2020.

Aceito em 03 de dezembro de 2020.

Publicado em 11 de dezembro de 2020. 